\title{
Systemic corticosteroid monotherapy for clinically diagnosed acute rhinosinusitis: a randomized controlled trial
}

\author{
Roderick P. Venekamp MD PhD, Marc J.M. Bonten MD PhD, Maroeska M. Rovers PhD, \\ Theo J.M. Verheij MD PhD, Alfred P.E. Sachs MD PhD
}

\begin{abstract}
Background: Patients with acute rhinosinusitis are frequently encountered in primary care. Although corticosteroids are being increasingly used for symptom control, evidence supporting their use is inconclusive. We conducted a randomized controlled trial to examine the effectiveness of systemic corticosteroid monotherapy for clinically diagnosed, uncomplicated acute rhinosinusitis.
\end{abstract}

Methods: We conducted a block-randomized, double-blind, placebo-controlled clinical trial at 54 primary care practices (68 family physicians) in the Netherlands between Dec. 30, 2008, and Apr. 28, 2011. Adult patients with clinically diagnosed acute rhinosinusitis were randomly assigned to receive either prednisolone $30 \mathrm{mg} / \mathrm{d}$ or placebo for 7 days and asked to complete a symptom diary for 14 days. The primary outcome measure was the proportion of patients with resolution of facial pain or pressure on day 7 .

Results: Of the 185 patients included in the trial (93 in the treatment group, 92 in the placebo group), 2 withdrew from the study and 9 were excluded from the primary analysis because of incomplete symptom reporting. The remaining 174 patients ( 88 in the treatment group, 86 in the placebo group) were included in the intention-to-treat analysis. The proportions of patients with resolution of facial pain or pressure on day 7 were $62.5 \%$ $(55 / 88)$ in the prednisolone group and $55.8 \%$ $(48 / 86)$ in the placebo group (absolute risk difference $6.7 \%$, 95\% confidence interval $-7.9 \%$ to $21.2 \%$ ). The groups were similar with regard to the decrease over time in the proportion of patients with total symptoms (combined symptoms of runny nose, postnasal discharge, nasal congestion, cough and facial pain) and health-related quality of life. Adverse events were mild and did not differ significantly between the groups.

Interpretation: Systemic corticosteroid monotherapy had no clinically relevant beneficial effects among patients with clinically diagnosed acute rhinosinusitis.

Netherlands Trial Register registration no. 1295 (www.trialregister.nl/trialreg/index.asp).
A cute rhinosinusitis is a common reason to visit a family physician. ${ }^{1,2}$ In primary care, the diagnosis is based on clinical signs and symptoms, ${ }^{3}$ because the added value of laboratory tests and imaging techniques is either too low or the tests are not cost-effective. ${ }^{3-7}$ Symptoms usually last 2 to 4 weeks but can be unpleasant enough to impair daily functioning and reduce quality of life. ${ }^{8}$ This might explain the high antibiotic prescription rates. ${ }^{1,29}$ Although antibiotics were found to be beneficial in a subgroup of patients whose diagnosis was confirmed by computed tomography scan,,$^{10}$ current evidence indicates that the majority of patients with clinically diagnosed acute rhinosinusitis do not benefit from antibiotics. ${ }^{11}$

Acute inflammation of the paranasal mucosa, whether due to infection (viral or bacterial), allergens or idiopathic causes, is increasingly considered the predominant path in the development of acute rhinosinusitis. ${ }^{12-15}$ Corticosteroids used intranasally could be effective by attenuating the inflammatory response, although current evidence of their benefits is inconclusive. ${ }^{16,17}$ Systemic administration of corticosteroids may have advantages over intranasal use, such as higher therapeutic levels and no risk of poor deliverance because of nasal blockage. A recent Cochrane review of systemic corticosteroid therapy for acute rhinosinusitis reported a short-term beneficial effect. ${ }^{18}$ However, data were limited, and almost all of the participants had been recruited in secondary care.

We conducted a block-randomized, doubleblind, placebo-controlled trial to determine the effectiveness of systemic corticosteroid treat-
Competing interests: Marc Bonten has been an advisory board member for Pfizer Netherlands and has received a grant from Pfizer Netherlands for studies on pneumonia. Maroeska Rovers has participated in workshops and educational activities on otitis media organized by GlaxoSmithKline and received a grant from GlaxoSmithKline for a study on the microbiology of otitis media. Theo Verheij has received consultancy fees, and a grant for studies on pneumonia, from Pfizer Netherlands. Alfred Sachs has been an advisory board member for Chiesi Pharmaceuticals BV and has participated in educational activities on a smoking cessation strategy for family physicians organized by Pfizer Netherlands. No competing interests declared by Roderick Venekamp.

This article has been peer reviewed.

Correspondence to: Roderick P. Venekamp, r.p.venekamp@umcutrecht.nl

CMAJ 2012. DOI:10.1503 /cmaj.120430 
ment as monotherapy in adult patients who visited their family physician with clinically diagnosed, uncomplicated acute rhinosinusitis of at least 5 days' duration.

\section{Methods}

\section{Study design}

The trial was performed between Dec. 30, 2008, and Apr. 28, 2011, at 54 primary care practices (68 family physicians) in Zeeland, a province in the southwestern region of the Netherlands. The study was approved by the medical ethics committee of the University Medical Center Utrecht and the central committee on research involving human subjects of the Netherlands. Neither the family physicians nor the patients received financial reimbursement for participation in the study.

\section{Participants}

Patients aged 18 years and older who visited their family physician with symptoms of acute rhinosinusitis of at least 5 days' (maximum 12 weeks') duration were recruited. We considered patients to have acute rhinosinusitis if they met the criteria for a clinical diagnosis as defined in the European Position Paper on Rhinosinusitis and Nasal Polyps 2007 for primary care. ${ }^{3}$ Patients had to have at least 2 symptoms: one of either nasal discharge (anterior or posterior nasal drip) or nasal congestion; the other of either facial pain or pressure, or pain when masticating.

We excluded patients with a complicated course of acute rhinosinusitis (i.e., orbital swelling, temperature $\geq 38.5^{\circ} \mathrm{C}$ after 5 days of symptoms) and those with a history of recurrent rhinosinusitis ( $\geq 2$ episodes in the previous year). Other exclusion criteria were pregnancy, previous head and neck surgery for malignant disease, contraindication for prednisolone, and use of intranasal or oral corticosteroids in the previous 4 weeks.

\section{Randomization}

Sealed blind-sequenced medication containers that held a 7-day supply of either prednisolone $30 \mathrm{mg} / \mathrm{d}$ or placebo were distributed to participating practices in randomized blocks of 4 . The corticosteroid and placebo drugs, manufactured and tested by the pharmacy department of the University Medical Center Utrecht (independent of the trial team), were identical in taste and appearance. The containers were identifiable only by randomization code number. The pharmacy department created the block randomization sequence using computer-generated random numbers. The randomization code was kept at a locker in the pharmacy department throughout the study and was not broken until data collection was completed and blinded analyses were performed.

\section{Study protocol}

After obtaining informed consent, family physicians completed a baseline questionnaire about the participant's symptoms, comorbidities and consultations for acute rhinosinusitis in the 3 years before the study and performed a basic physical examination.

Each participant was then given a sealed medication container with a 7-day supply of either prednisolone or placebo and a diary to record symptoms for 14 days. The diary included questions about symptoms of asthma and rhinitis in the year before the study, ${ }^{19}$ the use of trial medication and other medication, their daily activities, and daily entries of 7 symptoms (facial pain or pressure, nasal congestion or blockage, postnasal discharge, runny nose, poor sleep, cough and reduced productivity). In addition, questions regarding disease-specific health-related quality of life from the Sino-Nasal Outcome Test 2020,21 were answered on days 1, 7 and 14. As part of both the daily entries of 7 symptoms and the Sino-Nasal Outcome Test 20, patients were asked to rate the severity of symptoms on a 6point scale $(0=$ normal or no problem, $1=$ very mild problem, $2=$ mild or slight problem, $3=$ moderate problem, $4=$ severe problem and $5=$ problem as bad as it can be).

The participants were allowed to use the following medications for symptom relief: acetaminophen $500 \mathrm{mg}$ (maximum 6 tablets daily) for as long as needed and xylometazoline $0.1 \%$ nasal spray for 7 days. Family physicians were allowed to prescribe antibiotics or intranasal corticosteroid treatment but were advised to refrain from doing so as much as possible during the first week of study.

During the initial days of study, a blood sample was taken on a voluntary basis for an allergen-specific IgE test to a panel of common aeroallergens in adults (Phadiatop). The results were classified as positive or negative.

On day 14 , patients visited their family physician for a consultation and handed in their symptom diary and medication container. The physician performed a physical examination and completed a questionnaire regarding consultations with the patient in the previous 2 weeks. At 8 weeks, the physicians were asked to complete a final questionnaire about consultations in the past 6 weeks; patients were contacted by telephone by the coordinating investigator to complete a questionnaire including questions from the Sino-Nasal Outcome Test 20. 


\section{Outcome measures}

The primary outcome measure was the proportion of patients with resolution of facial pain or pressure (score of 0 or 1 ) on day 7. Secondary outcome measures were the proportion of patients with resolution of severe facial pain or pressure (defined as absence of score of 4 or 5 regardless of severity score at baseline) on day 7 , the proportion with resolution of other clinically relevant symptoms on day 7 , time to resolution of total symptoms (combined symptoms of runny nose, postnasal discharge, nasal congestion, cough and facial pain), median duration of symptoms, health-related quality of life and resumption of daily activities (work or school).

\section{Statistical analysis}

Based on a previous trial, ${ }^{22}$ we expected $50 \%$ of the participants in the placebo group to have resolution of facial pain or pressure on day 7. To detect a clinically important difference in a selflimited condition in a primary care setting, we calculated a sample size of at least 184 patients based on the assumption of a minimum difference of $20 \%$ in the primary outcome between groups $^{23,24}(\alpha=0.05$ and $\beta=0.20)$.

For dichotomous outcomes, we calculated absolute risk differences, relative risks (RRs) and 95\% confidence intervals (CIs). We used binomial logistic regression analysis to adjust for observed differences in baseline characteristics. The Mann-Whitney $U$ test was used to evaluate differences in the median duration of symptoms between the groups. We calculated health-related quality of life by combining individual scores for the items on the Sino-Nasal Outcome Test 20, for a total score ranging from 0 to 100 . The Student $t$ test was used to evaluate differences in mean scores between groups at baseline, day 7 , day 14 and week 8 . We calculated the proportion of patients who resumed daily activities.

In post-hoc analyses, potential modification of the effect of corticosteroids was evaluated by means of binomial logistic regression analyses, including interaction terms for atopic status, allergic rhinitis, chronic nasal symptoms, re current rhinosinusitis, duration of symptoms before randomization and baseline severity of symptoms.

We also performed 2 sensitivity analyses: in one, we imputed missing data using multiple imputation ${ }^{25}$ in another, we changed the definition of resolution of total symptoms.

We performed all of the analyses according to the intention-to-treat principle, using SPSS version 17 and Rothman's Episheet version June 11, 2008 (www.drugepi.org/dope-downloads/\# Episheet).

\section{Results}

\section{Patient characteristics}

Of the 218 patients assessed for eligibility, 33 were excluded (Figure 1). The remaining 185 patients were randomly assigned to the prednisolone group $(n=93)$ and the placebo group $(n=92)$. The baseline characteristics are shown in Table 1 . The mean age was 43.9 years in the prednisolone group and 42.4 years in the placebo group. The median duration of symptoms before enrolment was 12 and 13.5 days, respectively. Except for sex and atopic status (positive Phadiatop test result), there were no clinically relevant differences in baseline characteristics between the groups (Table 1).

One patient in each group withdrew from the study on day 1 . Of the remaining 183 patients,

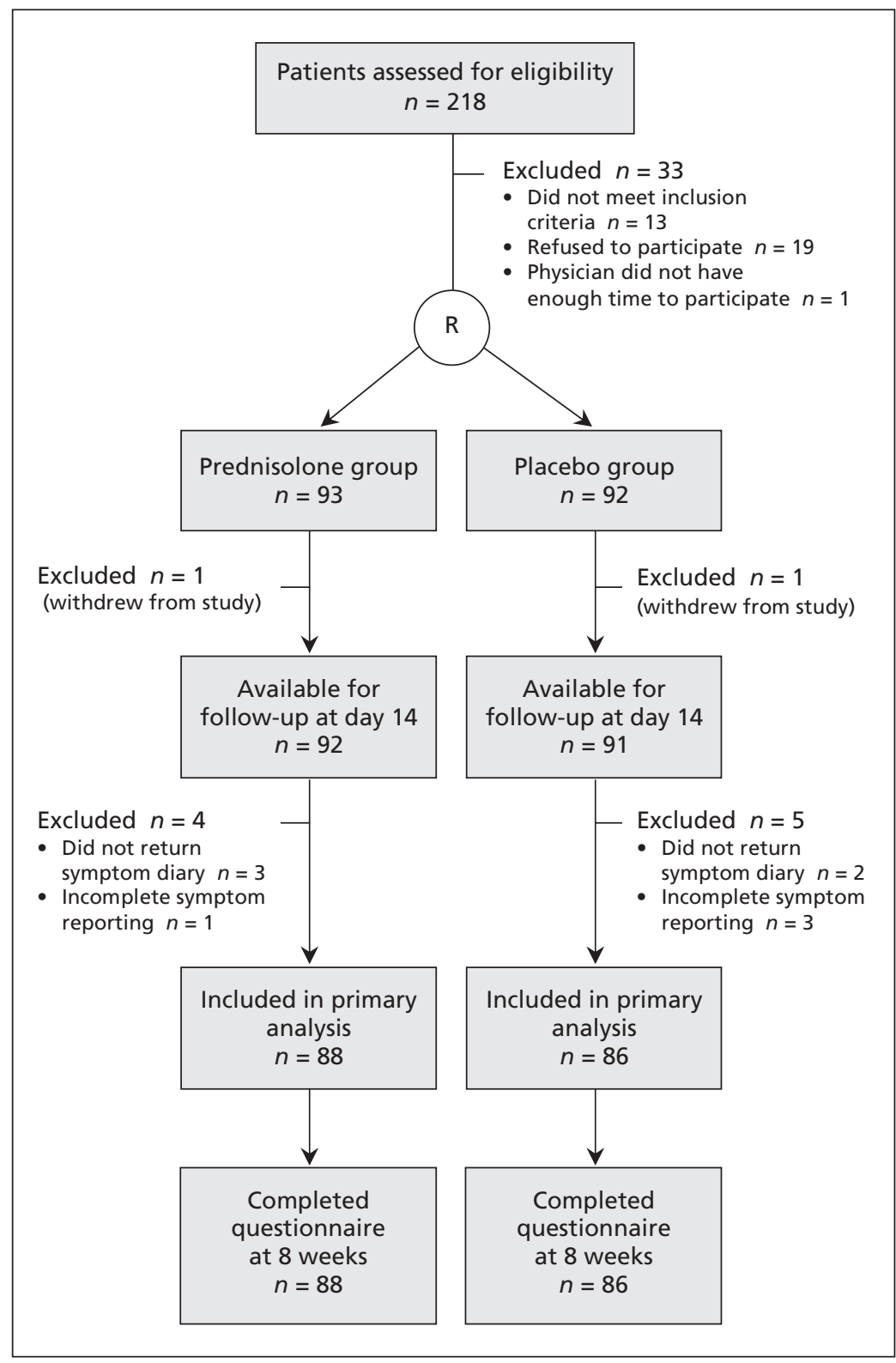

Figure 1: Flow of patients through the trial. $\mathbf{R}=$ randomization. 
$9(4.9 \%)$ were excluded because of missing data for the primary outcome. The remaining 174 patients (88 in the prednisolone group, 86 in the placebo group) were included in the primary analysis (Figure 1).

\section{Effect on outcomes}

The proportion of patients with resolution of facial pain or pressure on day 7 was $62.5 \%$ $(55 / 88)$ in the prednisolone group and $55.8 \%$ (48/86) in the placebo group (absolute risk difference $6.7 \%, 95 \%$ CI $-7.9 \%$ to $21.2 \%$ )

Table 1: Characteristics at enrolment of 185 patients with clinically diagnosed, uncomplicated acute rhinosinusitis

\begin{tabular}{|c|c|c|}
\hline \multirow[b]{2}{*}{ Characteristic } & \multicolumn{2}{|c|}{ Group; \% (no.) of patients* } \\
\hline & $\begin{array}{l}\text { Prednisolone } \\
\qquad n=93\end{array}$ & $\begin{array}{c}\text { Placebo } \\
n=92\end{array}$ \\
\hline Age, yr, mean (SD) & $43.9(13.6)$ & $42.4(13.7)$ \\
\hline Sex, female & $67.7(63 / 93)$ & $55.4(51 / 92)$ \\
\hline \multicolumn{3}{|l|}{ Smoking history } \\
\hline Never & $38.2(34 / 89)$ & $41.6(37 / 89)$ \\
\hline Former & $33.7(30 / 89)$ & $39.3(35 / 89)$ \\
\hline Current & $28.1(25 / 89)$ & $19.1(17 / 89)$ \\
\hline \multicolumn{3}{|l|}{ Medical history } \\
\hline Recent history of rhinosinusitis $\dagger$ & $32.6(30 / 92)$ & $32.2(29 / 90)$ \\
\hline Asthma & $6.5(6 / 92)$ & $8.9(8 / 90)$ \\
\hline Seasonal allergic rhinitis & $19.6(18 / 92)$ & $18.0(16 / 89)$ \\
\hline Eczema & $6.5(6 / 92)$ & $8.9(8 / 90)$ \\
\hline $\begin{array}{l}\text { Chronic obstructive pulmonary } \\
\text { disease }\end{array}$ & $1.1(1 / 92)$ & $1.1(1 / 89)$ \\
\hline Duration of symptoms, d, median (IQR) & $12(7-20)$ & $13.5(7-21)$ \\
\hline Initial temperature, ${ }^{\circ} \mathrm{C}$, median (IQR) & $36.7(36.3-37.0)$ & $36.7(36.3-37.0)$ \\
\hline Pus on inspection & $20.4(19 / 93)$ & $20.9(19 / 91)$ \\
\hline Postnasal drip on inspection & $19.3(17 / 88)$ & $16.7(15 / 90)$ \\
\hline Nasal congestion & $83.9(78 / 93)$ & $84.8(78 / 92)$ \\
\hline Facial pain or pressure & $95.7(89 / 93)$ & $95.7(88 / 92)$ \\
\hline Unilateral & $36.5(27 / 74)$ & $39.5(30 / 76)$ \\
\hline Bilateral & $63.5(47 / 74)$ & $60.5(46 / 76)$ \\
\hline Severity of facial pain, score, $\neq$ mean (SD) & $3.0(1.3)$ & $3.1(1.4)$ \\
\hline \multicolumn{3}{|l|}{$\begin{array}{l}\text { Severity of problem according to } \\
\text { physician }\end{array}$} \\
\hline Mild problem & $28.0(26 / 93)$ & $30.3(27 / 89)$ \\
\hline Moderate problem & $67.7(63 / 93)$ & $68.5(61 / 89)$ \\
\hline Severe problem & $4.3(4 / 93)$ & $1.1(1 / 89)$ \\
\hline \multicolumn{3}{|l|}{ Laboratory measurement } \\
\hline $\begin{array}{l}\text { Positive result of Phadiatop test } \\
\text { (atopic status) }\end{array}$ & $35.4(29 / 82)$ & $27.3(21 / 77)$ \\
\hline \multicolumn{3}{|c|}{$\begin{array}{l}\text { Note: IQR = interquartile range, SD = standard deviation. } \\
\text { *Unless stated otherwise. } \\
\text { tConsultation with physician because of rhinosinusitis in the } 3 \text { years before the study. } \\
\text { †Score assigned by patient }(0=\text { no problem, } 1=\text { very mild problem, } 2=\text { mild problem, } \\
3=\text { moderate problem, } 4=\text { severe problem, } 5=\text { problem as bad as it can be). }\end{array}$} \\
\hline
\end{tabular}

(Table 2). Imputation of the 9 missing outcomes led to similar results (absolute risk difference $7.1 \%, 95 \%$ CI $-7.2 \%$ to $21.4 \%$ ). Resolution of the other clinically relevant symptoms did not differ significantly between the groups except for the proportion of patients with resolution of severe facial pain or pressure on day 7 , which was higher among those receiving prednisolone (absolute risk difference $10.6 \%, 95 \%$ CI $1.0 \%$ to $20.2 \%)$.

The median duration of facial pain did not differ between the prednisolone and placebo groups (4.5 v. 5 days, $p=0.8$ ) (Table 3 ). When we analyzed the duration of total symptoms (combined symptoms of runny nose, postnasal discharge, nasal congestion, cough and facial pain), we found a difference of 2 days in favour of prednisolone, which was not statistically significant (median 9 v. 7 days in the placebo group, $p=0.2$ ). The decrease over time in the proportion of patients with total symptoms was similar in both groups (Figure 2). Health-related quality of life did not differ significantly between the groups at different follow-up points. Resumption of daily activities at work or school over time was comparable in both groups.

The proportions of patients with resolution of facial pain and total symptoms at 8 weeks were higher in the placebo group than in the prednisolone group, although the difference was not statistically significant (absolute risk difference for resolution of facial pain $-2.2 \%$, $95 \% \mathrm{CI}-12.6 \%$ to $8.1 \%$; for resolution of total symptoms $-9.9 \%, 95 \%$ CI $-24.7 \%$ to $4.9 \%$ ) (Figure 2).

Binomial logistic regression analyses to adjust for sex and atopic status revealed effect estimates similar to those in the unadjusted analyses. No statistically significant interaction effects were found in the subgroup analyses.

During the 8 weeks of follow-up, we observed no significant difference in the frequency of consultations for acute rhinosinusitis between the prednisolone group (20.5\% [18/88]) and the placebo group (24.4\% [21/86]). In addition, the prednisolone and placebo groups did not differ significantly in the proportion of patients who received prescriptions for antibiotics (19.3\% [17/88] and $18.6 \%$ [16/86], respectively) or intranasal corticosteroids (18.2\% [16/88] and $17.4 \%$ [15/86], respectively).

\section{Adverse events}

During the trial, 2 serious adverse events not related to drug use were reported but were not considered reasons for unblinding. Other reported adverse events were mild and did not differ between the groups (Table 4). 


\section{Interpretation}

In this randomized, double-blind, placebocontrolled trial in primary care practices, we found no clinically relevant effect of systemic corticosteroid monotherapy among patients with clinically diagnosed, uncomplicated acute rhinosinusitis. Subgroup analyses revealed no significant interaction effects. Adverse events reported by participants were mild and did not differ between the groups.

A recent Cochrane review of systemic corticosteroid treatment revealed short-term beneficial effects among patients with acute rhinosinusitis. ${ }^{18}$ However, the methodologic quality of the included studies was judged to be moderate, and the independent effect of the corticosteroid therapy could not be determined because it was given as adjunctive therapy to oral antibiotic treatment in all of the studies. Moreover, 3 of the 4 studies were performed in secondary care and used radiologic assessment as part of the inclusion criteria.

A Cochrane review of intranasal corticosteroid treatment with or without antibiotics for acute rhinosinusitis confirmed by radiologic assessment or nasal endoscopy showed a very modest beneficial effect (for every 100 patients treated, 7 additional patients had complete or marked relief of symptoms at 15 to 21 days) ${ }^{26} \mathrm{~A}$ subsequent trial of intranasal corticosteroid monotherapy for clinically diagnosed acute rhinosinusitis reported no beneficial effect. ${ }^{16}$ It is unknown whether these findings could be explained by the poor delivery of corticosteroids because of blocked nasal passages or by the lack of anti-inflammatory effect in acute rhinosinusitis. Our study results indicate that the antiinflammatory effect of corticosteroids seems to be of no benefit in the broad population of patients with clinically diagnosed acute rhinosinusitis.

\section{Strengths and limitations}

Only 2 of the participants withdrew from the study, and less than $5 \%$ of patients had missing data on the primary outcome. Our choice of intervention (prednisolone $30 \mathrm{mg} / \mathrm{d}$ for 7 days) has been widely and successfully used in respiratory conditions with a major inflammatory com-

Table 3: Median duration of symptoms

\begin{tabular}{|c|c|c|c|c|}
\hline \multirow[b]{2}{*}{ Symptom } & \multicolumn{2}{|c|}{$\begin{array}{c}\text { Group; duration of } \\
\text { symptoms, d, median (IQR) }\end{array}$} & \multirow[b]{2}{*}{ Difference } & \multirow[b]{2}{*}{$p$ value* } \\
\hline & Prednisolone & Placebo & & \\
\hline Facial pain or pressure & $4.5(2-8)$ & $5(2-9)$ & 0.5 & 0.8 \\
\hline Nasal congestion & $4(2-7)$ & $4(2-9)$ & 0 & 0.8 \\
\hline Postnasal discharge & $3.5(1-8)$ & $3(1-8)$ & -0.5 & 0.7 \\
\hline Runny nose & $2(2-4)$ & $1(1-8)$ & 1 & 0.5 \\
\hline Cough & $2(1-5)$ & $3(1-8)$ & 1 & 0.046 \\
\hline Total symptoms $†$ & $7(4-\geq 14)$ & $9(6-\geq 14)$ & 2 & 0.2 \\
\hline 4 of 5 total symptoms & $5(3-8)$ & $6(3-11)$ & 1 & 0.1 \\
\hline 3 of 5 total symptoms & $3(2-5)$ & $4(2-7)$ & 1 & 0.2 \\
\hline
\end{tabular}

Table 2: Proportion of patients with resolution of symptoms on day 7 *

\begin{tabular}{|c|c|c|c|c|}
\hline \multirow[b]{2}{*}{ Symptom resolved } & \multicolumn{2}{|c|}{ Group; \% (no.) of patients } & \multirow[b]{2}{*}{$\begin{array}{l}\text { Absolute risk difference, } \\
\qquad \%(95 \% \mathrm{Cl})\end{array}$} & \multirow[b]{2}{*}{$\begin{array}{l}\text { Relative risk } \\
(95 \% \mathrm{Cl})\end{array}$} \\
\hline & $\begin{array}{l}\text { Prednisolone } \\
\quad n=88\end{array}$ & $\begin{array}{c}\text { Placebo } \\
n=86\end{array}$ & & \\
\hline Facial pain or pressure & $62.5(55 / 88)$ & $55.8(48 / 86)$ & 6.7 (-7.9 to 21.2$)$ & $1.12(0.87$ to 1.44$)$ \\
\hline Severe facial pain or pressuret & $93.2(82 / 88)$ & $82.6(71 / 86)$ & $10.6 \quad$ (1.0 to 20.2$)$ & $1.13(1.01$ to 1.26$)$ \\
\hline Nasal congestion & $57.5(50 / 87)$ & $53.5(46 / 86)$ & $4.0(-10.8$ to 18.8$)$ & $1.07(0.82$ to 1.40$)$ \\
\hline Runny nose & $69.3(61 / 88)$ & $58.1(50 / 86)$ & 11.2 (-3.0 to 25.3$)$ & 1.19 (0.95 to 1.50$)$ \\
\hline Cough & $66.3(57 / 86)$ & $54.8(46 / 84)$ & 11.5 (-3.1 to 26.1$)$ & 1.21 (0.95 to 1.55$)$ \\
\hline Total symptomsł & $32.9(28 / 85)$ & $25.3(21 / 83)$ & 7.6 (-6.1 to 21.3$)$ & $1.30(0.81$ to 2.10$)$ \\
\hline Severe total symptoms & $81.2(69 / 85)$ & $78.3(65 / 83)$ & 2.9 (-9.3 to 15.0$)$ & $1.04(0.89$ to 1.21$)$ \\
\hline 4 of 5 total symptoms & $44.7(38 / 85)$ & $39.8(33 / 83)$ & $5.0(-10.0$ to 19.9$)$ & $1.12(0.79$ to 1.60$)$ \\
\hline
\end{tabular}


ponent, such as exacerbations of asthma and chronic obstructive pulmonary disease..$^{27,28} \mathrm{We}$ did not use a dose of prednisolone greater than $40 \mathrm{mg} / \mathrm{d}$, because the increased risk of adverse effects would have been highly undesirable in a relatively mild, self-limited condition such as acute rhinosinusitis. ${ }^{29,30}$

Our study has limitations. First, we used a clinical diagnosis rather than radiologic assess-

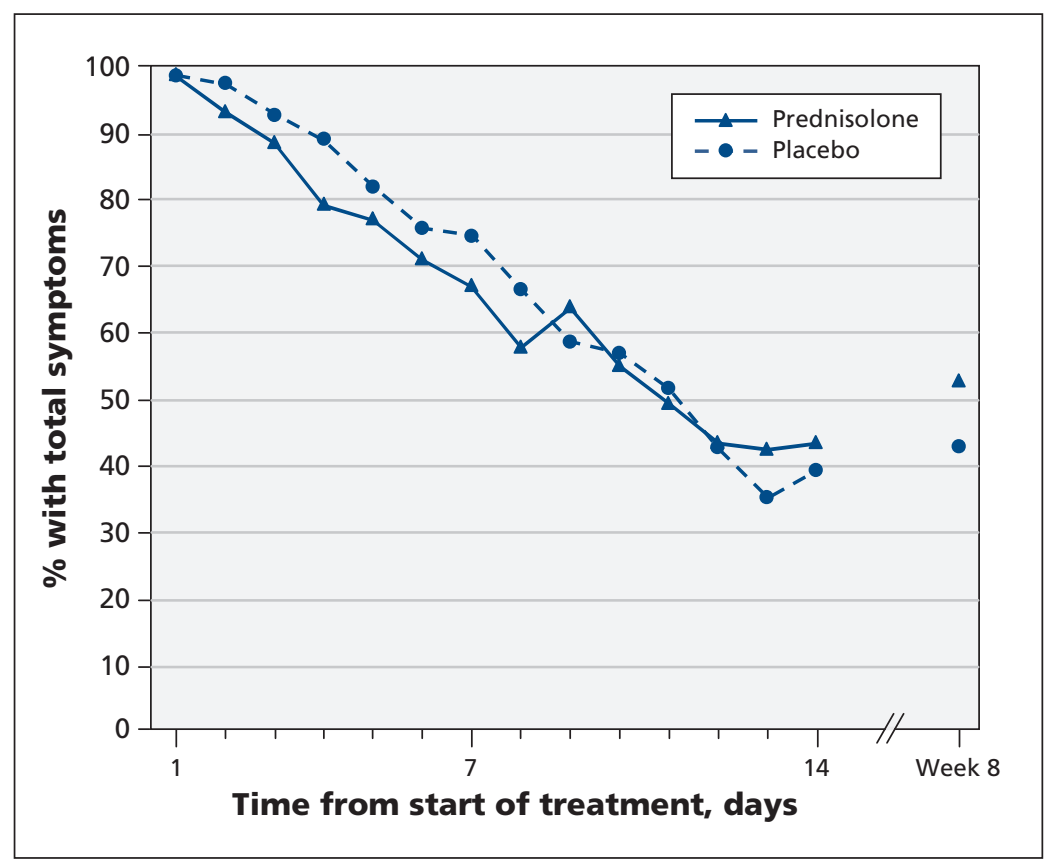

Figure 2: Proportion of patients who had combined symptoms of runny nose, postnasal discharge, nasal congestion, cough and facial pain during follow-up.

Table 4: Adverse events reported during the study*

\begin{tabular}{|c|c|c|c|}
\hline \multirow[b]{2}{*}{ Adverse event } & \multicolumn{2}{|c|}{ Group; no. of patients } & \multirow[b]{2}{*}{$p$ valuet } \\
\hline & $\begin{array}{l}\text { Prednisolone } \\
\quad n=88\end{array}$ & $\begin{array}{c}\text { Placebo } \\
n=86\end{array}$ & \\
\hline \multicolumn{4}{|l|}{ First week } \\
\hline Gastric complaint & $11 / 86$ & $8 / 84$ & 0.5 \\
\hline Diarrhea & $14 / 86$ & $10 / 85$ & 0.4 \\
\hline Increased appetite & $14 / 86$ & $7 / 84$ & 0.1 \\
\hline Mood disturbance & $13 / 83$ & $15 / 85$ & 0.7 \\
\hline Sleep disturbance & $24 / 85$ & $28 / 86$ & 0.5 \\
\hline \multicolumn{4}{|l|}{ Second week } \\
\hline Gastric complaint & $7 / 88$ & $5 / 85$ & 0.6 \\
\hline Diarrhea & $12 / 87$ & $8 / 86$ & 0.4 \\
\hline Increased appetite & $8 / 87$ & $3 / 85$ & 0.1 \\
\hline Mood disturbance & $9 / 88$ & $11 / 84$ & 0.6 \\
\hline Sleep disturbance & $12 / 87$ & $15 / 85$ & 0.5 \\
\hline \multicolumn{4}{|c|}{$\begin{array}{l}\text { *Two serious adverse events not related to drug use were reported: } 1 \text { hospital admission for } \\
\text { anemia on day } 49 \text { of the study in the placebo group and } 1 \text { hospital admission for wasp sting- } \\
\text { induced anaphylaxis on day } 28 \text { of the study in the prednisolone group. } \\
+\chi^{2} \text { test. }\end{array}$} \\
\hline
\end{tabular}

ment before randomization. Therefore, some of our patients may not have had radiologic evidence of acute rhinosinusitis. Previous metaanalyses of the effect of antibiotics in acute rhinosinusitis showed different results when radiologic assessment was part of the inclusion criteria, compared with clinical diagnosis alone. ${ }^{11,31}$ However, almost all patients with acute rhinosinusitis are seen in primary care, and radiologic imaging is not routinely performed in this setting before treatment decisions. Inclusion of patients based on radiologic assessment would therefore have strongly reduced the generalizability of our findings. Moreover, our study population is comparable to those in other primary care studies of acute rhinosinusitis. ${ }^{16,17,22}$ Our findings are therefore representative of the broad population of patients with clinically diagnosed, uncomplicated acute rhinosinusitis encountered in primary care.

Second, we performed complete case analysis because of the low number of missing data. However, missing data rarely occur completely at random, and complete case analysis may lead to loss of statistical power and biased results. ${ }^{32}$ We therefore performed a sensitivity analysis by imputing missing data. The results were similar to those of the primary analysis.

Third, our study was underpowered to detect statistically significant differences in subgroup analyses. Although we found no statistically significant interaction effect, post-hoc subgroup analysis of patients with chronic nasal symptoms revealed a strong trend toward beneficial effects of corticosteroids. In addition, we excluded patients who had used corticosteroids intranasally in the 4 weeks before enrolment. Based on the current evidence of the efficacy of intranasal corticosteroid treatment in allergic rhinitis, ${ }^{33}$ patients with acute rhinosinusitis who have this underlying condition may benefit from corticosteroids. Future research is needed to determine the efficacy of corticosteroid treatment in these subgroups of patients.

\section{Conclusion}

We found no clinically relevant effect of systemic corticosteroid monotherapy among patients with clinically diagnosed, uncomplicated acute rhinosinusitis. Future studies should focus on identifying subgroups of patients who may benefit from intranasal or systemic cortico steroid treatment. In the meantime, we feel that there is no rationale for the use of corticosteroids in the broad population of patients with clinically diagnosed acute rhinosinusitis and instead advocate symptomatic treatment. 


\section{References}

1. Kuyvenhoven M, van Essen G, Schellevis F, et al. Management of upper respiratory tract infections in Dutch general practice; antibiotic prescribing rates and incidences in 1987 and 2001. Fam Pract 2006;23:175-9.

2. Ashworth M, Charlton J, Ballard K, et al. Variations in antibiotic prescribing and consultation rates for acute respiratory infection in UK general practices 1995-2000. Br J Gen Pract 2005;55:603-8.

3. Fokkens W, Lund V, Mullol J. European position paper on rhinosinusitis and nasal polyps 2007. Rhinol Suppl 2007:1-136.

4. Laine K, Maatta T, Varonen H, et al. Diagnosing acute maxillary sinusitis in primary care: a comparison of ultrasound, clinical examination and radiography. Rhinology 1998;36:2-6.

5. Lindbaek M, Hjortdahl P, Johnsen UL. Use of symptoms, signs, and blood tests to diagnose acute sinus infections in primary care: comparison with computed tomography. Fam Med 1996;28:183-8.

6. Hansen JG, Schmidt H, Rosborg J, et al. Predicting acute maxillary sinusitis in a general practice population. BMJ 1995;311: 233-6.

7. van Duijn NP, Brouwer HJ, Lamberts H. Use of symptoms and signs to diagnose maxillary sinusitis in general practice: comparison with ultrasonography. BMJ 1992;305:684-7.

8. Meltzer EO, Hamilos DL, Hadley JA, et al. Rhinosinusitis: establishing definitions for clinical research and patient care. J Allergy Clin Immunol 2004;114(Suppl):155-212.

9. Hickner JM, Bartlett JG, Besser RE, et al. Principles of appropriate antibiotic use for acute rhinosinusitis in adults: background. Ann Intern Med 2001;134:498-505.

10. Lindbaek M, Hjortdahl P, Johnsen UL. Randomised, double blind, placebo controlled trial of penicillin $\mathrm{V}$ and amoxycillin in treatment of acute sinus infections in adults. BMJ 1996;313:325-9.

11. Young J, De SA, Merenstein D, et al. Antibiotics for adults with clinically diagnosed acute rhinosinusitis: a meta-analysis of individual patient data. Lancet 2008;371:908-14.

12. Winstead W. Rhinosinusitis. Prim Care 2003;30:137-54

13. Snow V, Mottur-Pilson C, Hickner JM. Principles of appropriate antibiotic use for acute sinusitis in adults. Ann Intern Med 2001; 134:495-7.

14. Baroody FM, Mucha SM, deTineo M, et al. Nasal challenge with allergen leads to maxillary sinus inflammation. J Allergy Clin Immunol 2008;121:1126-32.

15. Kirtsreesakul V, Naclerio RM. Role of allergy in rhinosinusitis Curr Opin Allergy Clin Immunol 2004:4:17-23.

16. Williamson IG, Rumsby K, Benge S, et al. Antibiotics and topical nasal steroid for treatment of acute maxillary sinusitis: a randomized controlled trial. JAMA 2007;298:2487-96.

17. Meltzer EO, Bachert C, Staudinger H. Treating acute rhinosinusitis: comparing efficacy and safety of mometasone furoate nasal spray, amoxicillin, and placebo. J Allergy Clin Immunol 2005;116:1289-95.

18. Venekamp RP, Thompson MJ, Hayward G, et al. Systemic corticosteroids for acute sinusitis. Cochrane Database Syst Rev 2011; (12):CD008115

19. Asher MI, Keil U, Anderson HR, et al. International Study of Asthma and Allergies in Childhood (ISAAC): rationale and methods. Eur Respir J 1995;8:483-91.

20. Pynnonen MA, Kim HM, Terrell JE. Validation of the SinoNasal Outcome Test 20 (SNOT-20) domains in nonsurgical patients. Am J Rhinol Allergy 2009;23:40-5.

21. Piccirillo JF, Merritt MG Jr, Richards ML. Psychometric and clinimetric validity of the 20-Item Sino-Nasal Outcome Test (SNOT-20). Otolaryngol Head Neck Surg 2002;126:41-7.

22. Stalman W, van Essen GA, van der Graaf Y, et al. The end of antibiotic treatment in adults with acute sinusitis-like complaints in general practice? A placebo-controlled double-blind randomized doxycycline trial. Br J Gen Pract 1997;47:794-9.
23. Damoiseaux RA, van Balen FA, Hoes AW, et al. Primary care based randomised, double blind trial of amoxicillin versus placebo for acute otitis media in children aged under 2 years. BMJ 2000;320:350-4

24. Burke P, Bain J, Robinson D, et al. Acute red ear in children: controlled trial of non-antibiotic treatment in general practice. BMJ 1991;303:558-62

25. Barnes SA, Lindborg SR, Seaman JW Jr. Multiple imputation techniques in small sample clinical trials. Stat Med 2006;25:233-45.

26. Zalmanovici A, Yaphe J. Intranasal steroids for acute sinusitis. Cochrane Database Syst Rev 2009;(4):CD005149.

27. Walters JA, Wang W, Morley C, et al. Different durations of corticosteroid therapy for exacerbations of chronic obstructive pulmonary disease. Cochrane Database Syst Rev 2011;(10): CD006897.

28. Walters JA, Gibson PG, Wood-Baker R, et al. Systemic corticosteroids for acute exacerbations of chronic obstructive pulmonary disease. Cochrane Database Syst Rev 2009;(1):CD001288.

29. Warrington TP, Bostwick JM. Psychiatric adverse effects of corticosteroids. Mayo Clin Proc 2006;81:1361-7.

30. Williamson PM, Kelly JJ, Whitworth JA. Dose-response relationships and mineralocorticoid activity in cortisol-induced hypertension in humans. J Hypertens Suppl 1996;14:S37-41.

31. Ahovuo-Saloranta A, Borisenko OV, Kovanen N, et al. Antibiotics for acute maxillary sinusitis. Cochrane Database Syst Rev 2008;(2):CD000243.

32. Donders AR, van der Heijden GJ, Stijnen T, et al. Review: a gentle introduction to imputation of missing values. J Clin Epidemiol 2006;59:1087-91

33. Nielsen LP, Dahl R. Comparison of intranasal corticosteroids and antihistamines in allergic rhinitis: a review of randomized, controlled trials. Am J Respir Med 2003;2:55-65.

Affiliations: From the Julius Center for Health Sciences and Primary Care (Venekamp, Bonten, Rovers, Verheij, Sachs), and the Departments of Otorhinolaryngology (Venekamp), and Medical Microbiology (Bonten), University Medical Center Utrecht, Utrecht, the Netherlands; and the Department of Operating Rooms (Rovers), Radboud University Medical Center Nijmegen, Nijmegen, the Netherlands

Contributors: All of the authors had full access to the data and take responsibility for the integrity of the data and the accuracy of the analyses. Marc Bonten, Theo Verheij and Alfred Sachs were responsible for the study concept and design. Marc Bonten, Maroeska Rovers, Theo Verheij and Alfred Sachs supervised the study. Roderick Venekamp acquired the data. All of the authors contributed to the analysis and interpretation of the data. Roderick Venekamp drafted the manuscript, and the other authors reviewed it critically for intellectual content. All of the authors approved the final version submitted for publication.

Funding: This study was supported by a grant from the Netherlands Organisation for Health Research and Development (ZonMw grant no. 170881007). The agency did not participate in the design and conduct of the trial, or the collection, management, analysis and interpretation of the data, nor did it have a role in the preparation, review or approval of the manuscript.

Acknowledgement: The authors thank all of the family physicians and patients who participated in the trial. 